GLOBAL JOURNAL OF EDUCATIONAL RESEARCH VOL 12, 2013: 1-8

COPYRIGHT@ BACHUDO SCIENCE CO. LTD PRINTED IN NIGERIA. ISSN 1596-6224 www.globaljournalseries.com; Info@globaljournalseries.com

\title{
EFFECTS OF MATERIAL AND NON-MATERIAL REINFORCERS ON ACADEMIC PERFORMANCE OF GIRLS ON HEALTH SCIENCE IN THE SENIOR SECONDARY SCHOOLS IN ABIA STATE
}

\author{
C. AMUMA AND N. B. IDOLI \\ (Received15, August 2012; Revision Accepted 9, January 2013)
}

\begin{abstract}
This study examined effects of material and non-material reinforcers on academic performance of Abia State Senior Secondary Schools girls on health science. As a quasi-experimental study, 120 SS II students were selected from six secondary schools located in the three Educational zones of the state. From each zone, two schools were selected using stratified random sampling. The 240 students were divided into three groups of 80 students each. That is, 80 to the material reinforcer group, 80 to the non-material reinforcer and 80 to the control group. The lessons developed on health science were content validated and the reliability was established at 0.86 coefficient index. The students in the material reinforcer, non-material reinforcer and control group were taught differently according to the specification of the study. Before the treatment, pre-test were conducted and after the teaching exercises, post-test were conducted. The results of the tests calculations based on ANOVA, and z-test indicated that three hypotheses were rejected and one was accepted. Some of these findings were made; that the mean scores of students materially reinforced and students that were non-materially reinforced differ significantly, meaning that the former had higher achievement score more than the later and the mean scores of students taught using material reinforcement differ significantly from the control group. Based on the findings and conclusions, some recommendations made; to ensure good improvement in the studentsô performance in health science, teachers should always consider it necessary to use material reinforcers in teaching their students and that government should always provide these tangible materials for the teachers to use in teaching health science.
\end{abstract}

\section{INTRODUCTION}

The spate of poor performance of Nigerian students in especially the sciences has remained a source of worry to government and other stakeholders in education. Adaji (2005) noted that failure rates in both school and public examinations have been distressingly high and studentsôperformance at every level of education has continued to be low. This downward trend in the performance of students especially girls is blamed on the teachersôin appropriate teaching methods and their inability to use reinforcement to encourage their studentsôperformance.
Reinforcement may be positive or negative, which ever way, it elicits change in behaviour. According to Amuma (2010) reinforcement has produced an enormous body of reproducible experiment results. Reinforcement is the central concept and procedure in the experimental analysis of behaviour and much of quantitative analysis of behaviour. Reinforcement may be positive reinforcement when there is increase in the future frequency of behaviour due to the addition of a stimulus (reinforcer) following a response. While negative reinforcement increases the future frequency of a behaviour

\footnotetext{
C. Amuma, Department of Curriculum Studies and Educational Technology, University of Port Harcourt , Port Harcourt, Nigeria

N. B. Idoli, Department of Educational Administration/Planning, University of Calabar, Calabar, Nigeria
} 
when the consequences is removed of an aversive stimuli (Kennedy and Mount, 1986). Nwankwo (2005) emphasized that these consequences could be pleasurable to the organism and thus strengthen or encourage the repetition of such behaviour. Also, he maintained that the consequences could be aversive or unpleasant to the organism and thus, reducing the occurrence of the proceeding behaviour.

Cotton (2006) and Nwankwo (2005) in their various works maintained that pleasurable consequences are generally called reinforcers, while unpleasant ones are called punishers. These reinforcers may come in form of material reward such as pencil, bic, ruler, edibles and other tangible items. It can be non-material which may come inform of praise, clapping hand, smile and others. As contained in Students First (2002:1) r̃material reinforcers can be highly motivating for some children and adolescents though each young person differs significantly in what kind of material reinforcers interest them.

Laboratory and field experiments have demonstrated the effectiveness the effectiveness of reinforcement and success in spelling that the use of reinforcement to improve the academic achievement of normal children in regular classroom settings appears to have been less intensively investigated. While the issue of whether material rewards should be given for academic achievement is by no means of recent origin, empirical evidence on the use of material rewards in a typical classroom is scanty.

In Nigeria, many studies on the performance of boys and girls in the sciences indicated more poor performance by the girls. Salau (1995), Ojerinde (1998), Fakorode (1999) and Alamina (2001) all reported the superiority of male students compared to their female colleagues in science achievement. Also, Adeoye and Sotayo (2003) studied performance in secondary school physics and concluded that boys performed better than girls. With the problem of poor performance by girls in the sciences, which many attributed to the teachers inability to use reinforcers (material and nonmaterial) in teaching science subjects. This study therefore investigated the effects of material and non-material reinforces on the academic achievement of girls in health science.

\section{PURPOSE AND OBJECTIVES OF THE STUDY}

The main aim of this study is the investigation of the effects of material and nonmaterial reinforcers on the performance of senior secondary school female students in health science. In more specific terms; the study was guided by these objectives:

1. To determine if there is any difference in pre-test and post-test mean scores of female students taught health science using material reinforcers using material reinforcers.

2. To determine if there is any difference in the pre-test and post-test mean scores of female students taught health science using non-material reinforcers.

3. To determine if any difference exists between the pretest and post test mean scores of female students in the control group taught health science using no reinforcers.

4. To determine if any difference exists between the post test mean scores of female students taught health science using material, non-material reinforcers and those taught without any of the reinforcers.

\section{RESEARCH QUESTIONS}

These research questions guided the study:

1. Is there any difference in the pre-test and post test mean scores of female students taught health science using material reinforcers?

2. Is there any difference in the pretest and posttest scores of female students taught health science using non material reinforcers?

3. What is the difference between the pretest and post test mean scores of female students taught health science using no reinforcers?

4. Is there any difference in the post test mean scores of female students taught health science using material reinforcers, non-material reinforcers and those taught using no-reinforcesr?

\section{NULL HYPOTHESES}

1. There is no significant difference in the pretest and post test mean performance of female students taught health science using material reinforcers.

2. There is no significant difference in the pretest and post test female students taught health science using non-material reinforcers. 
3. There is no significant difference in the pre-test and post-test mean performance of female students taught health sciences using no reinforcers.

4. There is no significant difference in the post test mean performance of female students taught health science using material reinforcers, non-material reinforcers and no reinfocer.

\section{SIGNIFICANCE OF THE STUDY}

This study which concentrated on the use of material, non-material and no reinforcers in teaching health science to female students are beneficial in many ways; it provide information on how material and non-material reinforcers can enhance the performance of female students in health science.

Also, it provided a bridge between our perception and reality and pointed out the way to enhance female positive appreciation of science subjects at the secondary school level.

\section{THEORETICAL FRAMEWORK}

This study is anchored on the principle of reinforcement developed from the theory of reinforcement by Thorndike (1975), Skinner (1954) and others. Skinner cited in Byron (2008), Finton (2006) believed that human behaviours could be controlled or modified by the principle of reinforcement. The behavioural theorists concerned themselves with the relationship between any particular response and the consequences that preceded it. The behavioural theorists Thorndike, Skinner and others cited in Byron (2008) maintained that man is primarily a product of learning shaped by external variables, genetic factors and environmental influences on man⿳亠丷 behaviour. The behaviourists emphasized on the prediction and control of observable and measurable behaviour followed by a reinforcing stimulus resulting in an increase in the probability of the future occurrence of that behaviour and consequently, behaviour devoid of reinforcing stimulus and this results in a decreased probability of the future occurrence of such behaviour.

\section{THE CONCEPT OF REINFORCEMENT}

Based on the foregoing, Sheffield (2006) defined reinforcement as a process of shaping behaviour by controlling the consequences of the behaviour. Nwankwo (2005) and Bluestein (2004) respectively maintained that reinforcement is the addition of pleasant stimulus to a situation or the withdrawal of an unpleasant stimulus from a situation in order to increase the proceeding response. In reinforcement, combinations of rewards and or punishments are used to reinforce desired behaviour.

Nwankwo (2005) further explained that behaviour of people is normally influenced by its immediate consequences of reinforcement. He argued that those consequences could be pleasurable to the organism and thus strengthen or encourage the repetition of such behaviour or the consequences could be aversive or unpleasant to the organism and thus, reduces the occurrence of the proceeding behaviour.

The pleasurable consequences, Nwankwo (2005), Cotton (2006) referred to as reinforcers are any consequences that increase the frequency of behaviour. Reinforcement could be positive or negative, a positive reinforcement is whenever the presentation of an event following an operant increases the probability of the occurrence of the operant in a similar situation. While negative reinforcement is the process of removal of a specific event following an operant, which increases the likelihood that the operant will occur again.

Slarvin (1988) noted that reinforcers that are escape from unpleasant situation are referred to as negative reinforcers while a positive reinforcer is a stimulus that increases the probability of a response or behaviour occurring when added to a response or behaviour occurring when added to a situation.

These reinforcers which may be material or non-material increases the change in the behaviour of the learners when properly handled by the teacher. This means that the consistent poor achievement in health education by students can be minimized if these reinforcers by the health education teachers, this is the gap this study intend to close.

\section{MATERIAL AND NON-MATERIAL REINFORCERS}

Cotton (2007) on material reinforcers noted that material reinforces include symbolic reward such as gold stars, having one $\hat{\Phi}$ picture on a bulletin board or name in a news letter and token rewards such as chips which are value les in themselves but which can be redeemed for things of value as well as tangible rewards such as edible, toys, pencils and note books. While 
non-material reinforcers are verbal reinforcement which includes praise, smile and time free of going on field trip (Cotton, 2007). Non-material reinforcers also include t̃humbs up, a compliment, a pat on the balk, encouragement, recognition and an approving smilesò (Studentsô First, 2012).

Various studies using material and nonmaterial reinforcers confirmed their effectiveness. Bear (2006) in this research which concentrated on reinforce methods effectiveness discovered that contingent verbal reinforcement is more effective than other methods for older students and whether immediate or delayed reinforcement, it is more effective mainly in a matter of the developmental level of the recipient. Young children respond best to immediate reinforcement while older students respond equally to immediate and delayed reinforcement. O\&eary and O\&eary (1997) found in their study that softly delivered, firm reprimands for misbehaviour were more effective than yelling.

\section{RESEARCH METHODOLOGY}

The study was a pre-test, posttest and control group design. The population for the study comprised the 839 female SSII students offering health science in the 189 secondary schools located in the three educational zones of Abia State. The sample consisted of 120 students offering health science selected from six secondary schools (two from each of the three educational zones in the state). The schools were selected through stratified random sampling technique based on the three educational zones. Based on these three strata, the students were selected using random sampling technique.
The instrument for the study was teacher made test in health science based on endo and ecto parasites. The test items consisted of 44 items. Before instruction, a test retest method was used to determine the reliability of the instrument. The correction coefficient was computed through the use of Pearson Product Moment Correlation Coefficient and established at 0.87 . During instruction, the material and nonmaterial reinforcers groups were taught using material and non-material reinforcers and the conventional group were taught with out any reinforcers.

The students were pre-tested and the scores obtained consisted the pretest scores students in the two experimental groups were taught non-material reinforcers tape worn, round worm, liver fluke and parasitic relations withy the application of material and non-material reinforcers. While those in the control group were taught without the application of reinforcers. Thirty lesson periods were covered and the posttest administered, the scores were analyzed using mean, SD, t-test and ANOVA.

\section{RESULT}

\section{Research Question One:}

Is there any difference in the pre-test and post-test mean scores of female students taught health science using material reinforcers?

\section{Null Hypothesis One:}

There is no significant difference in the pretest post test mean performance of female students taught health science using material reinforcers.

Table 1: Z-test Result of the Test and Post Test Performance of Female Students Taught Health Science Using Material Reinforcers.

\begin{tabular}{|c|c|c|c|c|c|c|c|c|c|}
\hline $\begin{array}{l}\text { Pre-Test Post Results of } \\
\text { Female Students in the } \\
\text { Material Reinforcer Group }\end{array}$ & $\mathbf{N}$ & $\bar{X}$ & SD & D & $\begin{array}{l}\text { Sign. } \\
\text { Level }\end{array}$ & $\begin{array}{l}\text { Standard } \\
\text { Error }\end{array}$ & $\begin{array}{l}\text { Z- } \\
\text { cal. }\end{array}$ & Z-crit. & Result \\
\hline Pretest Result & 40 & 41 & 15.7 & \multirow[b]{2}{*}{38} & & & \multirow{2}{*}{\multicolumn{2}{|c|}{2.042}} & \\
\hline Post test result & 40 & 65 & 16.5 & & 0.05 & 3.6 & & & Significant \\
\hline
\end{tabular}

Z-Calculated value $=6.7$

Z-Critical value $=2.042$

Decision: Hypothesis of no significant rejected.

Table 1 above indicated that the female students in the material reinforcer group in their pretest recorded 41 mean score and $15.7 \mathrm{SD}$ and the post test result recorded 65 mean score and 16.5 SD. The z-test analysis conducted using a mean and standard deviation produce z-calculated value of 6.7 . Then, based on 38 DF and 0.05 significant level 2.042 z-critical values was achieved. 
This means that there was significant improvement in the performance of the female students when taught health science using material reinforcers.

\section{Research Question Two:}

Is there any difference in the pretest and post-test scores of female students taught health science using non-material reinforcer?

\section{Null Hypothesis Two:}

There is no significant difference in the pre-test and post-test mean performance of female students taught health science using non-material reinforcers.

Table 2: Z-test Result of the Pretest and Post-Test Performance of Female Students Taught Health Science Using Non-Material Reinforcers.

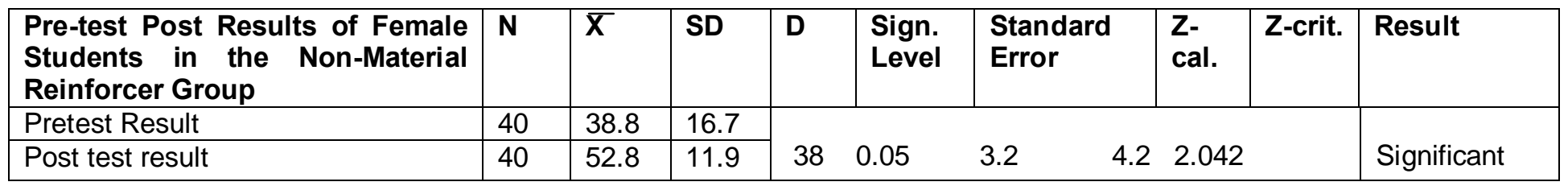

Z-Calculated value $=4.3$

Z- Critical value $=2.042$

Decision: Hypothesis of no significant rejected.

Table 2 showed that the female students in the non-material reinforcer group recorded 38.8 pre-test mean score and 16.7 SD. In their post-test score they recorded 52.8 mean score and 11.9SD. The mean scores were subjected to z-test analysis, 4.3 Z-calculated value was obtained. Also, based on 0.05 significant level and $38 \mathrm{DF}, 2.042 \mathrm{Z}$-calculated value achieved.

As the $z$-calculated value is greater than the $z$-critical value, the hypothesis of no significance is rejected. This means that the use of non-material reinforcers improved the academic performance of students in health science.

Research Question Three:

What is the difference in the pretest and post-test mean performance of female students taught health science using no reinforcers?

Null Hypothesis Three:

There is no significant difference in the pre-test and post-test mean performance of female students taught health science using no reinforcers.

Table 3: z-test Result of the Pretest and Post Test Performance of Female Students Taught Health Science Using No-Reinforcers.

\begin{tabular}{|l|l|l|l|l|l|l|l|l|l|}
\hline $\begin{array}{l}\text { Pre-Test Post Results of } \\
\text { Female Students in the No- } \\
\text { Reinforcer Group }\end{array}$ & $\mathbf{X}$ & $\mathbf{S D}$ & $\mathbf{D}$ & $\begin{array}{l}\text { Sign. } \\
\text { Level }\end{array}$ & $\begin{array}{l}\text { Standard } \\
\text { Error }\end{array}$ & Z-cal. & Z-crit. & Result \\
\hline Pretest Result & 40 & 37 & 20.5 & $\mathbf{3 8}$ & $\mathbf{0 . 4 5}$ & $\mathbf{4 . 2}$ & $\mathbf{1 . 8 1}$ & $\mathbf{2 . 0 4 2}$ & $\begin{array}{l}\text { Not } \\
\text { significant }\end{array}$ \\
\hline Post test result & 40 & 44.6 & 16.9 & & & & & &
\end{tabular}

Z-Calculated value $=1.81$

$Z$ - Critical value $=2.042$

Decision: Hypothesis of no significance Accepted. 
Table 3 presentation indicated that the female students in the reinforcer group recorded 37 mean score and 20.5 SD in their pretest 44.6 mean score and 16.9 SD. The result of z-test calculation showed that $1.81 \mathrm{z}$-calculated value was obtained. Then, based on 38 DF and 0.05 significant level, 2.042 was achieved. As the z-critical value is greater than the z-calculated value, the hypothesis of no significance is accepted.

\section{Null Hypothesis Four:}

There is no significant difference in the post test mean performance of female students taught health science using material reinforcers, non-material reinforcers and no-reinforcers.

Table 4: Analysis of Variance of Academic Mean Scores of Female Students in the Material NonMaterial and No Reinforcer Groups.

\begin{tabular}{|c|c|c|c|c|c|c|c|}
\hline Variance & SS & DF & Ms & F-Ratio & F-Critical & LS & Result \\
\hline Between groups & 8799.616667 & 2 & 18094.1875 & \multirow{3}{*}{58.5} & \multirow{3}{*}{3.09} & \multirow[b]{3}{*}{0.05} & \multirow[b]{3}{*}{ Significant } \\
\hline Within groups & 36188.375 & 117 & 309.3024 & & & & \\
\hline Total & 44987.991667 & 119 & & & & & \\
\hline
\end{tabular}

From the F-distribution table, the critical value of $\mathrm{F}$ based on 2 and 117 degrees of freedom at 0.05 level of significance achieved 3.09-critical value. As the computer F-value, the hypothesis of no significance is rejected. This means that there is a significant difference in the mean scores of female students taught health science using material reinforces, non-material reinforcers and no-reinforcers.

\section{Findings}

Based on the analysis of data, the following findings were made:

1. That the use of material reinforcers in teaching health science produced the best performance in the female students.

2. Also the use of non-material reinforcers improved the performance of female students in health science.

3. The study discovered significant difference in the performance of female students health science using material reinforcers, non-material reinforcers and no-reinforcers.

4. That slight improvement was recovered by the female students taught health science using no-reinforcers.

\section{DISCUSSION}

The first finding of this study indicated that the use of material reinforcers in teaching health science produced the best performance in the female students. This actually shows that female students if taught science subjects with material rewards will do very well. Moreso, the poor performance of female students reported by some studies could be as a result of lack of understanding of the psychology of the female students and the use of approaches which do not encourage competition among the students. This finding confirmed the finding made by Amuma (2010), Bear (2004), Nwoergu (2006) in their studies discovered that material rewards elicited more positive rewards in students more than any other form of reward.

This finding means that with proper use of material rewards, female students performance in the science subjects would improve. Also, many of them would drop their negative attitudes toward the study of science subjects.

The second finding made by this study showed that the use of non-material reinforcers also improved the performance of female students in health science. This finding indicated that the use of praises, verbal commendations, simile, clapping of hands can motivate students positive performance in their subjects especially, the science subjects. Adaji (2005) in her study on the effect of verbal reinforcement strategy on academic achievement of poor achieving students in English language showed that female students taught with verbal reinforcement performed better than the male students taught with verbal reinforcement. Although, Cotton (2001) in his study on the effects of praise on studentsô academic performance, his finding indicated that praise may be helpful, neutral or 
detrimental depending on the kind of praise it is and the context in which it is delivered.

Obviously, the use of praise as a reinforcer can produce positive outcome in the academic performance of female students if used in a right context and in an appropriate time.

The third finding of this study discovered significant difference in the performance of female students taught health science using material reinforcers, non-material reinforcers and no reinforcer. The female students in the material reinforcer group produced more positive result than those in the non-material and no-material reinforcer groups. Amuma (2010) in her study on the effects of material, non-material and noreinforcer on the academic performance of students discovered that the use of material reinfocers improved more than others the performance of the students. Bernard (1992) also noted that material reinforcers or the use of tangible rewards elicit more positive academic performance in the learners.

Finally, the study discovered that the use of no-reinforcers produced slight improvement in the pretest and post test results of students in the no-reinforcer group. This slight improvement in performance may as a result of mastery of the content by the students due to the explanations offered by $t$ he teacher during the classroom activities or as a result of the learning environment.

\section{Recommendations}

1. Teachers in teaching health science or other science subjects should use material reinforcers in teaching their student.

2. That the combination of material and non-material reinforcers in the classroom would encourage female students to study hard their science subjects.

3. That female students who produce outstanding results in their results should be rewarded materially so that this can make other students to work harder.

4. Teachersô who employ material reinfocers or effectively combine them with non-material reinfocers should also be encouraged by the government through promotion.

\section{REFERENCES}

Cotton, K., 2001. Instructional Reinforcement School Improvement Research Series.

Adeoye, F. A. and Sotayo, M. A. O., 2003. The Effect of Locus of Control and Gender on Senior Science School Academic Achievement in Physics. The Nigerian Teacher. A Journal of Teacher Education, 11(1). 95-102.

Finton, D. J., 2006. Reinforcerment Learning. File://g:/unclesimon/whatis reinforcementlearning.htm.

Students First. 2012. Positive Reinfocerment. Internet Downloaded Material.

Galloway, C. G. and Thomson, E. W., 2012. Material Reinforcement and Success in Spelling. Internet Down Loaded Material.

Byron, A., 2008. Positive and Negative Reinforcement. Blackwell Publishing.

Adaji, T. O., 2005. Effects of Verbal Reinforcement Strategy on Academic Achievement of Poor Achieving Pupils in the English Language in the Primary Schools: A Case Study of Olamaboro Local Government Area, Kogi, State. A Multi-Disciplinary Journal, Vol. 11, No. 2, November.

Alamina, J. I., 2001. An Impediment to Women in Science: Cultural Influence and the Way Forward. 42 and Annual Conference Proceedings of the STAN. Ibadan: Heinemann Educational Books.

Bear, G. C., 2006. Interdependent Grouporiented Contingency System for Improving Academic Performance, School Psychology. Review a 190-193.

Bernard, H. W., 1992. Psychology of Learning and Teaching. New York: McGrew Hell Inc.

Bluestein, J., 2004. Practical Strategies for Working Successfully with Difficult Students. New York: Blireau of Education and Research. 
Cotton, 2006. Instructional Reinforcement, the Schooling Practices that Matter Most in School. Improvement, Research Series U.S.A.

Cotton, 2007. Instructional Reinforcement: The Schooling Practices that Matter most School. Improvement Research Series, U. S. A.

Ekeh, P. U., 2004. Gender Bias and Achievement in Science and Mathematics Among Primary School Pupils: Implications for Human Resource Development. Nigeria Journal of Curriculum Studies, Vol. 11, No.2.

Fakoro Nwankwo, O. C., 2005. Effects of Study Habits Counselling on Acadmeic Performance of Secondary School Students in Rivers State. Journal of Counseling and Communication, Vol. 1, No.2.

Nworgu, B. G., 2006. Evaluating the Effects of Resources Material Types Relative to Studentsô Cognitive Achievement, Retention and Interest in Integrated Science. Unpublished Doctoral
Dissertation, Nsukka: University of Nigeria Library.

Okeary, K. D. and Odeary, S. G., 1997. The Successful of Behaviour Enhancement Reward. New York: Pergamon Press.

Fakorode, A. D., 1999. A Survey into Gender Difference and Students Achievement is Secondary School Biology: A Cause Study of Oyo State. Unpublished M.ED Dissertation. Ibadan: University of lbadan.

Ojerinde, D., 1998. Under-Achievement in School Science in Nigeria. African Journal of Education, 1 (1), 176-191.

Salau, M. O., 1995. An Analysis of Students Enrolment and Performance in Mathematics at Senior School Certificate Level. JASK, 5 (1), 147-149.

Slavin, R. E,, 1986. Educational Psychology Theory into Practice. Englewood Cliffs. NJ Prentice-Hall.

Thorndike, E., 1975. The Educational Psychology: The Psychology of Learning. New York: Teachers College Press. 